\title{
Khối đại học đứng đầu về tiềm năng nghiên cứu ở Việt Nam
}

\author{
Bùi Diệu Quỳnh \\ Viện Khoa học Giáo dục Việt Nam, Bộ Giáo dục và Đào tạo
}

Khoa học \& Phát triển (07/11/2019 11:45); http://khoahocphattrien.vn/khoa-hoc/khoi-dai-hocdung-dau-ve-tiem-nang-nghien-cuu-o-viet-nam/20191107101827141p1c160.htm

Các cơ quan có số lượng nghiên cứu nhiều nhất đều là các trường đại học hoạt động dưới cơ chế tự chủ, và một tỷ lệ không nhỏ là các trường đại học tư thục - dữ liệu từ Web of Science/Publons cho thấy.

Mới đây, trong danh sách các cơ quan nghiên cứu thuộc cơ sở dữ liệu Publons, một tiêu chí mới đã được cập nhật là tổng số các nghiên cứu có trong Core Collection của ISI Web of Science (WOS), bao gồm các danh mục con: $\mathrm{SCIE} / \mathrm{SSCl} / \mathrm{AHCl} / \mathrm{ESCl}$ cho tạp chí học thuật, $\mathrm{CPCl}$ cho kỷ yếu hội nghị, và chỉ mục $\mathrm{BCl}$ cho sách. Dựa trên thông tin này, tiềm năng khoa học của một số cơ quan nghiên cứu tại Việt Nam có thể được quan sát sơ qua như ở bảng dưới.

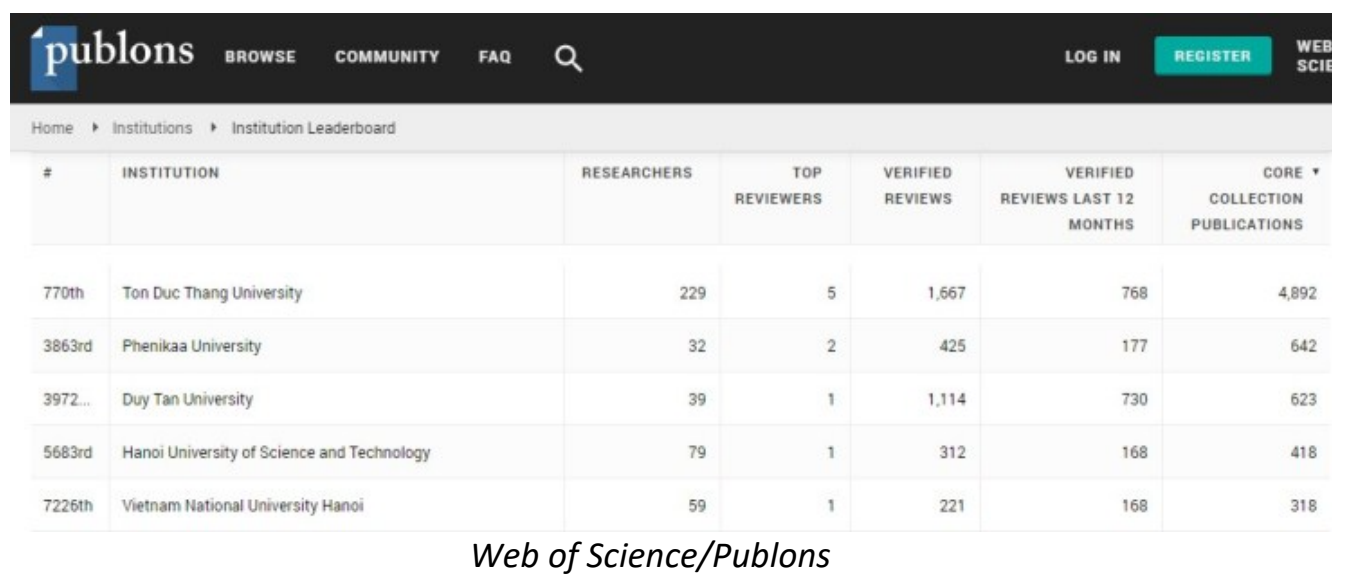

Cần lưu ý, số lượng công bố trong WOS Core Collection này được cộng dồn tất cả các công bố trong quá khứ của các nhà nghiên cứu hiện đang làm việc tại cơ quan được liệt kê, bất kể cơ quan trong bài báo là ở đâu. Bên cạnh đó, một số đặc tính của dữ liệu như độ trễ, mức độ khai báo thông tin của người dùng, cũng khiến con số có thể chưa đầy đủ, mà có tính "bảo thủ", tức là phản ánh thấp hơn thực tế. Chính vì thế, chúng ta nên quan sát con số này với tính chất dự báo tiềm năng khoa học của một cơ quan nghiên cứu, thông qua đại diện là con người -- các nhà nghiên cứu đang công tác tại đó. 
Bảng 1. Tiềm năng khoa học của một số cơ quan / trường đại học Việt Nam theo dữ liệu Web of Science/Publons

\begin{tabular}{|c|c|c|c|}
\hline $\begin{array}{l}\text { Trường đại học/Cơ quan } \\
\text { nghiên cứu Việt Nam }\end{array}$ & Nhà nghiên cứu & $\begin{array}{l}\text { Số nghiên cứu } \\
\text { trong WOS Core } \\
\text { Collection }\end{array}$ & $\begin{array}{l}\text { Nhà bình duyệt } \\
\text { xuất sắc/báo cáo } \\
\text { bình duyệt }\end{array}$ \\
\hline Trường ĐH Tôn Đức Thắng & 229 & 4892 & $5 / 1664$ \\
\hline Trường ĐH Phenikaa & 32 & 642 & $2 / 425$ \\
\hline Trường ĐH Duy Tân & 39 & 623 & $1 / 1114$ \\
\hline $\begin{array}{l}\text { Trường ĐH Bách Khoa Hà } \\
\text { Nội }\end{array}$ & 80 & 422 & $1 / 312$ \\
\hline ĐH Quốc gia Hà Nội & 59 & 318 & $1 / 221$ \\
\hline $\begin{array}{l}\text { ĐH Quốc gia TP. Hồ Chí } \\
\text { Minh }\end{array}$ & 52 & 291 & $1 / 196$ \\
\hline $\begin{array}{l}\text { Viện Hàn lâm KH\&CN Việt } \\
\text { Nam (VAST) }\end{array}$ & 27 & 267 & $0 / 50$ \\
\hline Viện Vật lý, VAST & 8 & 265 & $0 / 0$ \\
\hline $\begin{array}{l}\text { Trường ĐH Công nghệ } \\
\text { TPHCM-HUTECH }\end{array}$ & 6 & 210 & $2 / 342$ \\
\hline $\begin{array}{l}\text { Viện Khoa học Máy tính } \\
\text { (INCOS), ĐH Tôn Đức Thắng }\end{array}$ & 18 & 210 & $0 / 14$ \\
\hline $\begin{array}{l}\text { Học viện Công nghệ Bưu } \\
\text { chính Viễn thông }\end{array}$ & 13 & 175 & $0 / 4$ \\
\hline $\begin{array}{l}\text { Trường ĐH Nguyễn Tất } \\
\text { Thành }\end{array}$ & 8 & 164 & $1 / 204$ \\
\hline $\begin{array}{l}\text { Trường ĐH Bách Khoa, Đại } \\
\text { học Quốc Gia TPHCM }\end{array}$ & 71 & 154 & $0 / 64$ \\
\hline ĐH Huế & 26 & 149 & $0 / 22$ \\
\hline $\begin{array}{l}\text { Trường ĐH Khoa học tự } \\
\text { nhiên, ĐH Quốc gia Hà Nội }\end{array}$ & 40 & 140 & $0 / 4$ \\
\hline Viện Toán học, VAST & 5 & 104 & $0 / 9$ \\
\hline $\begin{array}{l}\text { Trường ĐH Bách khoa, ĐH } \\
\text { Đà Nẵng }\end{array}$ & 12 & 101 & $0 / 3$ \\
\hline Trường ĐH Sư phạm Hà Nội & 21 & 98 & $0 / 5$ \\
\hline Trường ĐH mở TPHCM & 15 & 92 & $0 / 35$ \\
\hline Trường ĐH Dược Hà Nội & 8 & 89 & $0 / 0$ \\
\hline ĐH Cần Thơ & 38 & 81 & $0 / 45$ \\
\hline
\end{tabular}

Dữ liệu truy cập ngày: 15:21 PM, 05-11-2019.

Từ đường dẫn: https://publons.com/institution/?country=99\&order by=num cc publications 
Điểm đáng chú ý đầu tiên là nhóm các cơ quan có số lượng nghiên cứu nhiều nhất, về cơ bản, đều là các trường đại học hoạt động dưới cơ chế tự chủ, và một tỷ lệ không nhỏ là các trường đại học tư thục. Không chỉ vậy, các cơ quan này cũng đóng góp nhiều báo cáo bình duyệt được xác nhận nhất.

Bên cạnh đó, cũng có nhiều viện nghiên cứu "con" nhưng có số lượng công bố không thua kém gì cơ quan "mẹ", ví dụ như Viện Vật lý và Viện Hàn lâm Khoa học và Công nghệ Việt Nam (VAST). Tuy nhiên, con số này có thể thay đổi khi các cơ quan được cập nhật dữ liệu đầy đủ hơn.

So sánh với một bảng xếp hạng khác được công bố gần đây là Nature Index, có thể thấy, hầu hết các cơ quan nằm trong top 10 cơ sở nghiên cứu ở lĩnh vực khoa học tự nhiên, hoá học, khoa học sự sống, khoa học trái đất và môi trường tại Việt Nam của bảng xếp hạng này cũng đều được cơ sở Publons ghi nhận ở các vị trí tiên phong như Viện Hàn lâm Khoa học và Công nghệ Việt Nam (VAST), trường ĐH Duy Tân, trường ĐH Bách khoa Hà Nội, ĐH Quốc gia TPHCM, trường ĐH Tôn Đức Thắng, trường ĐH Khoa học tự nhiên - ĐH Quốc gia Hà Nội [1].

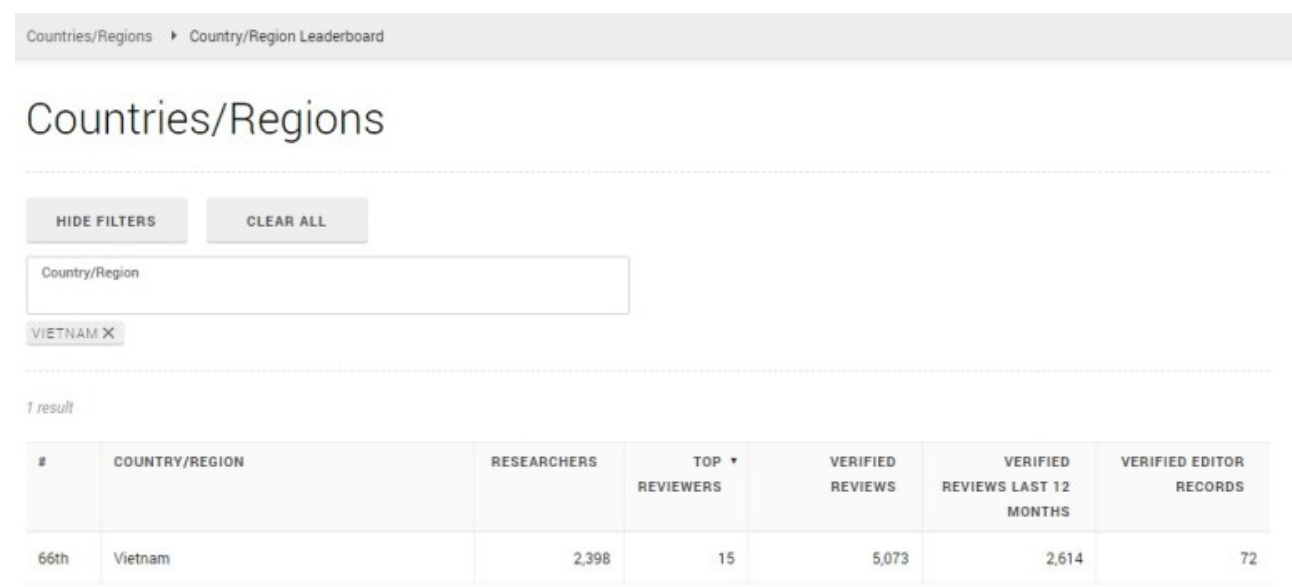

Web of Science / Publons

Khi đứng cùng nhau, sức mạnh của từng cơ quan nghiên cứu đã giúp Việt Nam cải thiện vị thế trên bình diện quốc tế.

(Tham khảo: https://publons.com/country/?country=99\&order by=top reviewers)

Chi tiết hơn, với 15 nhà bình duyệt xuất sắc, Việt Nam được xếp thứ 66; theo xếp hạng các báo cáo bình duyệt được xác nhận, Việt Nam xếp thứ 57 với 5.073 báo cáo. Các cây bút bình duyệt Việt Nam cũng đã hoạt động rất "chăm chi" trong 12 tháng qua với 2.614 báo cáo, xếp thứ 50 . Ngay cả tại mặt trận còn mới mẻ như biên tập khoa học, chúng ta cũng xếp thứ 77 với 72 báo cáo biên tập được xác nhận. Thực tế, các con số này có thể tăng cao hơn nữa chỉ bằng cách đơn giản: cập nhật và chăm sóc hồ sơ Publons cá nhân. Trong tương lai, sự chủ động trong quản lý hồ sơ khoa học sẽ giúp ích rất nhiều cho quá trình nâng tầm khoa học Việt Nam [2].

Trước đó, vào tháng 10, báo cáo Global Research Report - South and East Asia do ISI công bố, đã nêu tên Việt Nam với tư cách là quốc gia có tốc độ tăng trưởng học thuật nhanh nhất ở khu vực Nam và Đông Nam Á kể từ năm 2009. Dữ liệu phục vụ cho báo cáo này cũng được trích xuất từ ISI WOS. 
Sau khi được Clarivate Analytics mua lại từ Thomson Reuters vào năm 2016, ISI WOS đã có nhiều sự thay đổi để đáp ứng nhu cầu và sự cạnh tranh của thị trường. Nổi bật nhất là nỗ lực kết nối thông tin giữa 3 vai trò quan trọng của một nhà khoa học là Tác giả (Author), Nhà bình duyệt (Reviewer), và Biên tập viên (Editor) thông qua các CSDL là Web of Science (các văn bản khoa học đã xuất bản chính thức), với ScholarOne Manuscripts (hệ thống xử lý công tác biên tập các bản thảo đang trong quá trình bình duyệt), và Publons (CSDL các cây bút bình duyệt và các cây biên tập).

Mới nhất, ResearcherID Database của Thomson Reuters cũ nay cũng đã tích hợp với Publons, biến CSDL này trở thành nơi truy cập và tra cứu dữ liệu hồ sơ công bố ISI WOS đáng tin cậy nhất. Một số NXB danh tiếng và giàu tài nguyên, như Science và Nature, có thể cung cấp các số đo trích dẫn ISI WOS cho các bài đăng trên các tạp chí của họ, tuy nhiên đây là con số gộp, chỉ có ý nghĩa xác nhận tính hợp lệ của dữ liệu, chứ không cung cấp chi tiết nguồn. Nhưng Publons cho phép truy nguyên nguồn gốc từng số đếm trích dẫn, nếu bài được đăng trên tạp chí thuộc Core Collection của ISI WOS.

\section{Tham khảo:}

[1] Vietnam Higher Education Advancing Research Team (VHEART). (2019). Bản tin Giáo dục Đại học Tháng 10 năm 2019. Bộ Giáo dục và Đào tạo. Retrieved from http://chuongtrinhkhgd.moet.gov.vn/content/tintuc/Lists/news/Attachments/4705/B\% E1\%BA\%A3n\%20tin\%20GD\%C4\%90H\%20T10 2019.pdf

[2] Vuong, Q. H. (2019). Breaking barriers in publishing demands a proactive attitude. Nature Human Behaviour, 3(10), 1034. doi: 10.1038/s41562-019-0667-6. 